\title{
Relationship between Split-Step Timing and Leg Stiffness in World-Class Tennis Players when Returning Fast Serves
}

\author{
Sami Mecheri ${ }^{1}$, Guillaume Laffaye ${ }^{2,3}$, Céline Triolet ${ }^{2,3}$, David Leroy ${ }^{4}$, Matt Dicks ${ }^{5}$ \\ Mohamed A. Choukou ${ }^{6}$, Nicolas Benguigui ${ }^{7}$
}

${ }^{1}$ Laboratory for Road Operations, Perception, Simulators and Simulation IFSTTAR, Université Paris-Est, France

${ }^{2}$ CIAMS, Univ. Paris-Sud, Université Paris-Saclay, 91405 Orsay Cedex, France

${ }^{3}$ CIAMS, Université d'Orléans, 45067, Orléans, France

\footnotetext{
${ }^{4}$ CETAPS Laboratory, Faculty of Sports Sciences, UniRouen, Normandie Université, France

${ }^{5}$ Department of Sport and Exercise Science, University of Portsmouth, United Kingdom

${ }^{6}$ Center for Interdisciplinary Research in Rehabilitation and Social Integration, Department of Rehabilitation, Université Laval, Canada

${ }^{7}$ CESAMS Laboratory, University of Caen Normandie, France
}

\section{Accepted for Publication in Journal of Sports Sciences on the $4^{\text {th }}$ April, 2019}

\section{Corresponding Author}

Sami Mecheri

Laboratory for Road Operations, Perception, Simulators and Simulation

French Institute of Sciences and Technology for Transport, Development and Networks

Paris-Est University

14-20 Boulevard Newton, Cité Descartes

Champs sur Marne, F-77447 Marne la Vallée Cedex 2, France

Phone: +33181668346

E-mail: $\underline{\text { sami.mecheri@ifsttar.fr }}$

Word count (excluding acknowledgements and references): 7070 


\begin{abstract}
This study investigated split-step timing when returning serves and whether this timing is related to neuromechanical capabilities in world-class tennis players. In Experiment 1, the split-step timing of four groups of world-class players (male and female ATP/WTA seniors, and ITF juniors) was measured on court when returning serves of the same level players. The four groups initiated the split-step at a similar time, starting around the time ball-racket contact in the serve stroke and landed when early ball-flight information was available. In Experiment 2, the neuromechanical capabilities (leg stiffness and vertical jump performance) of a group of world-class players and three groups of less-skilled tennis players were examined. The results showed an increase in leg stiffness with an increase in level of expertise. A crossexperiment analysis in world-class male players $(\mathrm{ATP} / \mathrm{ITF}, \mathrm{n}=10)$ revealed that the timing of initial foot movement was significantly correlated with the leg stiffness $\left(r^{2}=0.54\right)$, with later lateral step after the serve in the players who had higher stiffness. The findings support the hypothesis that world-class tennis players adapt perceptual-motor control on the basis of their neuromechanical capabilities and maximise the time before initiating their interceptive action to rely on more reliable information.
\end{abstract}

Keywords: Perception, Action, Interception, Expertise, Spring-mass model 


\section{Relationship between Split-Step Timing and Leg Stiffness in World-Class Tennis Players when Returning Fast Serves}

The performance of dynamic interceptive actions is highly challenging because of the restrictive spatiotemporal constraints on performance. In sports situations such as the tennis serve-return, the available time for returning a serve hit at $200 \mathrm{~km} \cdot \mathrm{h}^{-1}$ is less than $600 \mathrm{~ms}$ (Abernethy \& Wollstein, 1989). With such spatiotemporal pressure, that impose a highly challenging constraint on the returning tennis stroke, it is remarkable that expert players are still able to return the ball in a large number of situations ( $80 \%$ of serve-returns are in the court at Grand Slam level, see Gillet, Leroy, Thouvarecq, \& Stein, 2009).

A first proposition to explain this ability was based on the assumption that expert racket sports players possess superior reaction times to produce shorter response latencies. However, research using non-sport-specific reaction time measures (e.g., press a key as soon as possible in response to a stimulus) has not revealed consistent differences between experts and novices (e.g., in badminton and squash players: Abernethy, 1991; in tennis players: Rowe \& McKenna, 2001). Research has also focused on athletes' anticipation ability. An extensive body of literature illustrates skilled performers' superiority over less-skilled athletes in perceptual judgment tests of anticipation skill (Williams \& Ward, 2007). In tennis, expert players have been shown to make better predictions of serve direction than novice players based on advance kinematic information (i.e., pre-ball-flight: Farrow \& Abernethy, 2003) and younger players based on situational probability information (i.e., patterns of opponent play: Farrow \& Reid, 2012). This advantage in anticipatory skill is thought to provide expert tennis players with the opportunity to initiate an accurate movement response before an opponent's stroke. 
A recent attempt to quantify the prevalence of anticipation during professional tennis matches (involving current or former top 20 ATP players) revealed, however, that the observed frequency of anticipatory behaviour (defined as lateral motion of the racket, the hips, the shoulders or the feet before the opponent's stroke) was relatively low, occurring between only $6 \%$ and $13 \%$ of all match situations (including passing shots, return and volley, see Triolet, Benguigui, Le Runigo, \& Williams, 2013). Although prior research demonstrated that collegiate tennis players did not move before ball-racket contact when facing live groundstrokes (Shim, Carlton, Chow, \& Chae, 2005), a striking finding in the study by Triolet et al. (2013) was the low level of anticipation (less than 10\%) in elite players when returning first serves, which are known to create pressing spatiotemporal constraints. This finding was interpreted as possible evidence of a 'conservative' strategy used by players in which they wait for information emanating from early ball flight before initiating responses. Importantly, the results from Shim et al. (2005) and Triolet et al. (2013) both revealed no response errors (i.e., moving to the wrong side) when participants initiated their responses after the opponent contacted the ball.

Shim et al. (2005) also revealed that the response latencies of skilled performers were significantly earlier when returning balls hit by a live opponent than when returning balls projected from a cloaked ball machine. Therefore, it seems possible that skilled performers use advance kinematic information not solely in order to anticipate the opponent's action, but also to reduce the response delay and get a better synchronisation of responses to the opponent's actions (Navia, Dicks, van der Kamp, \& Ruiz, 2017).

Few studies have examined the preparatory leg movements of tennis players referred to as the split-step. This action corresponds to a small bound, which is timed 
relative to the opponent's stroke, in order to initiate a movement toward the ball. From a biomechanical perspective, the split-step allows players to increase ground reaction forces and the restitution of mechanical energy by taking advantage of the pre-stretch applied to the lower limbs extensors for a more explosive displacement (Nieminen et al., 2014). The mechanical efficiency of this "bouncing" phase can be assessed by measuring Leg Stiffness. Leg Stiffness is used to characterise whole lower extremity function in stance during bouncing gait, like hopping or running, based on a simple spring-mass model, which considers the human body as a mass on a massless spring (Blickhan, 1989; McMahon \& Cheng, 1990).

The timing of the split-step in skilled senior tennis players (national and regional French level) when returning first serves was first examined in a technical report by Avilès, Benguigui, Beaudoin and Godart (2002). This study revealed that the timing of the split-step take-off and landing were similar between expertise levels, occurring $40 \mathrm{~ms}$ before the stroke and $160 \mathrm{~ms}$ after the stroke, respectively. In a more recent report, a post-stroke take-off (+34 ms) and landing $(+151 \mathrm{~ms})$ were reported in male and female juniors with a high national ranking in their respective categories (Avilès, Pérez, Sanz, \& Navia, 2014).

Other research on the split-step has been undertaken in laboratory conditions using a light direction signal preceded by three preparatory light blinks (Nieminen, Piirainen, Salmi, \& Linnamo, 2014; Uzu, Shinya, \& Oda, 2009). Uzu et al. (2009) reported that male collegiate tennis players land approximately $180 \mathrm{~ms}$ after the signal in order to produce a quick and reliable lateral step toward the target. With earlier landing times, participants were able to reduce the total time to reach the target but they also made more errors in response accuracy. Furthermore, Nieminen et al. (2014), revealed that when male tennis players with a competitive background utilised a 
preparatory split-step action - in which they landed $208 \mathrm{~ms}$ after the direction signal - they required less time to reach the target ( $13.1 \%$ faster) than when they did not use a preparatory split-step.

Only a small number of studies have investigated Leg Stiffness in tennis players. During jumping and hopping tests, Durand, Ripamonti, Beaune, and Rahmani (2010) assessed Leg Stiffness in thirteen male regional tennis players (mean age $=23.0$ years) and reported values of $34.8 \mathrm{kN} \cdot \mathrm{m}^{-1}$ which were comparable to elite sprinters and significantly correlated to $20-\mathrm{m}$ sprinting speed and counter-movement jump height. Maquirriain (2013) found a mean value of $18.8 \mathrm{kN} \cdot \mathrm{m}^{-1}$ in ten players (nine men and one woman, mean age $=17.6$ years) competing at national or international level in a hopping task. Girard and Millet (2009) calculated a Leg Stiffness of 19.9 kN.m ${ }^{-1}$ during jumping and hopping tests in twelve young players (mean age $=13.6$ years), and reported no correlation between tennis level (ranking) and Leg Stiffness. Altogether, results are rather scattered with studies reporting similar Leg Stiffness values between young players of different ages (Girard \& Millet, 2009; Maquirriain, 2013) and rare data (but obviously higher values) in senior players (Durand et al., 2010; see also Girard, Lattier, Micallef, \& Millet, 2006). In addition, it is unclear from prior literature whether Leg Stiffness influences tennis-specific performance in elite senior players, requiring further work to ascertain whether a greater Leg Stiffness would result in more efficient on-court actions, and thus supports better performance.

To date, few studies have examined the timing of the split-step sequence when returning serves (Avilès et al., 2002, 2014) and although the neuromechanical parameters involved in the split-step have been studied in the laboratory (Nieminen et al., 2014; Uzu et al., 2009), no study has attempted to examine both aspects to provide a more complete understanding of this behaviour. This issue may be worth 
investigating in tennis to confirm and extend research from Dicks, Davids and Button, (2010) in soccer, who reported that goalkeepers who were more agile with shorter movement times were found to wait later before initiating their actions and saved more penalty kicks in comparison with less agile goalkeepers. This Leg Stiffness adaptation hypothesis is that expert interceptive performance is not rendered by providing a maximum time period to execute the action (i.e., an earlier response) irrespective of action capabilities, but in contrast, by scaling the timing of responses relative to one's own action capabilities in order to provide a maximum time period before initiating the response to use more reliable information (see also, Fajen, 2005). In this context, we conducted two experiments to investigate the split-step timing of world-class tennis players in a serve-return task (Experiment 1) and Leg Stiffness and vertical jump performance of world-class and less-skilled tennis players (Experiment 2). Further cross-experiment analysis was conducted on the relationship between split-step timing and the Leg Stiffness measures to determine whether world-class tennis players adapt perceptual-motor control to their neuromechanical capabilities.

\section{Experiment 1: Split-Step Timing in Serve-Return}

The objective of Experiment 1 was to examine the split-step timing of worldclass tennis players when facing fast serves. The serve-return task was used as it requires execution of the split-step with minimum timing error to satisfy the high spatiotemporal demands. Four groups of world-class tennis players were tested: male and female seniors and juniors. The innovative rationale for testing these groups was to provide a broader view of the timing of the split-step by examining possible differences between males and females and/or between juniors and seniors. In line with Shim et al. (2005) and Triolet et al. (2013), all groups of players were expected 
to initiate the split-step and lateral displacement movements after the racket-ball contact to rely on more consistent information (i.e., early ball flight) and avoid errors in decision-making (Dicks et al., 2010). In addition, while no significant split-step timing difference was expected between juniors and seniors in line with a previous finding (Avilès et al., 2002), greater consistency in split-step timing was expected in senior players as a result of a better attunement to the opponent's unfolding action.

\section{Method}

\section{Participants}

Twenty-two male and female world-class tennis players participated voluntarily and gave written informed consent. The players were recruited from the French Tennis Federation elite training program and were assigned to four groups: (i) senior females, (ii) senior males, (iii) junior females and (iv) junior males. Senior groups consisted of seven men (mean age $=27.1 \pm 4.9$ years) and five women (mean age $=22.4 \pm 3.9$ years) with an average duration of intense practice of $14.9 \pm 5.4$ and $10.4 \pm 2.3$ years, respectively. At the time of testing, senior players were all ranked in world top 500 ATP or WTA world rankings. Junior groups consisted of five men (mean age $=16.8 \pm 0.7$ years) and five women (mean age $=16.8 \pm 0.8$ years) with an average duration of intense practice of $7.6 \pm 2.2$ and $8.4 \pm 2.2$ years, respectively. Junior players were all in the top 100 ITF junior world rankings. All participants had normal or corrected-to-normal vision and were naïve with respect to the hypotheses under investigation. The experiment was approved by the local ethics committee Human Subject Review Board.

\section{Task and Procedure}


The experiment took place on a hard court. The participants had to return a series of 20 first serves in the advantage court diagonal executed by a participant from the same group. Servers produced fast first serves (without spin) as they would do in competition. Serves were directed to two targets $0.80 \mathrm{~m} \times 0.80 \mathrm{~m}$ delimitated in both corners (Left [ZSL] and Right [ZSR] Zones of Serve, see Figure 1). Ten serves were played down the centre of the court (ZSL) and 10 wide (ZSR) following a test script. In order to be used in the experiment, serves were required to land in the intended square in the service rectangle and satisfy speed requirements (between 140 and 170 $\mathrm{km} \cdot \mathrm{h}^{-1}$ in females and between 160 and $190 \mathrm{~km} \cdot \mathrm{h}^{-1}$ in males) measured with a speed gun (Stalker ATS sports radar, USA). All servers received feedback about their stroke performance after each trial (speed and accuracy). The trials for which the serves did not meet speed and location requirements were excluded from the analyses. The servereturns that did not lead to a performance score of a minimum of three points (ball into the opposite half court) were also ruled out to avoid analysing ineffective returns. On this basis, $12.1 \pm 2.6$ serve-return sequences were analysed in seniors and $9.8 \pm 2.4$ in juniors (mean $\pm \mathrm{SD}$ ). The mean speed of the selected serves was $154.0 \pm 6.8$ (juniors) and $160.3 \pm 7.4$ (seniors) km.h ${ }^{-1}$ in females, and $169.1 \pm 9.7$ (juniors) and $176.6 \pm 9.6$ (seniors) $\mathrm{km} \cdot \mathrm{h}^{-1}$ in males. Consistent with the speed requirements for serve selection, a 2 (Expertise) $\times 2$ (Gender) ANOVA on serve-speed data only revealed a significant main effect of Gender.

Participants were informed about the nature and response requirements of the task before undertaking a self-selected warm-up. They were told that they had to return serves as they would in a normal competition. No strict constraints were imposed on their initial positioning, except that they should be between zero and two metres from the baseline in order to avoid significant differences in the time available to return. 
After each trial, players were given feedback about their return accuracy with a figure showing the number of points assigned to the court area they reached (Figure 1).

\section{Video Filming}

Video footage of serves and returns were filmed by two $100 \mathrm{~Hz}$ cameras (Basler A600, 640 x 480 pixels) controlled and synchronised by acquisition software (StreamPix, i2S). The camera filming the returner was located on the opposite side of the court at $2.50 \mathrm{~m}$ from the single side-line and $1.50 \mathrm{~m}$ from the baseline, while the camera filming the server was located on the opposite side of the court at $1.15 \mathrm{~m}$ from the centre mark and $4 \mathrm{~m}$ from the baseline (see Figure 1). Both cameras were at a height of $1.25 \mathrm{~m}$ to enable a close-up film of the player.

\section{Coding}

Using a video analysis software (Dartfish 5.5, Fribourg, Switzerland), we visually identified and coded several events of each serve-return sequence with the moment of server-racket impact with the ball corresponding to $t=0$. This moment was identified as the first frame showing that the ball was hit by the server. Temporal variables are presented in the following section. Three different experimenters coded the sequence after having been informed about the procedure and the criteria for coding. In order to check coding reliability, the three observers independently coded the same 24 serve-return events. This procedure showed that $80 \%$ of events were identically coded by the three coders (i.e., same image reported) and differences for other events were two images or less (i.e., $20 \mathrm{~ms}$ ). Disagreements between the coders were discussed to improve the consistency of the coding for the rest of the data.

\section{Dependent Variables}

Serve-return performance was assessed with reference to a point-scale grid. The opposite half court of the returner was divided into discrete zones and each shot 
was scored using a point system that awarded higher values on deep returns (see Figure 1). The percentage of successful returns (i.e., in the court) was also calculated for each player.

Temporal variables. Three variables related to split-step timing were measured:

Split-step take-off corresponded to the frame at which the last of the player's feet in contact with the court had left the ground when initiating the split-step.

Split-step landing corresponded to the frame at which the first of the player's feet had touched the ground when completing the split-step.

Split-step duration was defined as the time between the split-step take-off and landing.

Two other variables related to the initiation of the lateral response to move toward the ball were calculated (see Triolet et al., 2013 for a similar method):

Initial racket movement was defined as the first frame when a directional movement of the racket toward the ball was observable.

Initial foot movement (or lateral step) was defined as the first frame when a directional movement of any of the player's feet toward the ball was observable.

The sampled values used to calculate each temporal variable were also employed to calculate their variability (i.e., standard deviation, SD).

\section{Statistical Analysis}

Serve-return performance, temporal variables, and variability of the temporal variables were analysed using a 2 (Expertise: junior, senior) $\times 2$ (Gender: females, males) factorial ANOVA. Descriptive statistics were reported using the mean and the 
standard deviation (mean $\pm \mathrm{SD}$ ). All tests were completed with $p$ set at .05 . The familywise error rate for the 10 ANOVAs on temporal variables and their variability was controlled using the Holm-Bonferroni step-down procedure by ranking the $p$-values from smallest to largest and comparing them to a sequentially adjusted alpha (Holm, 1979). To not only allow conservative conclusions about significant differences in the split-step timing, however, we considered the results that were significant by conventional standards but did not meet the Holm-Bonferroni adjusted alpha (alphaadj) as marginally significant. The assumption of homogeneity of variances was checked using a Levene test. Post-hoc analyses were conducted with Bonferroni-corrected pairwise comparisons. Partial eta-squared $\left(\eta_{\mathrm{p}}{ }^{2}\right)$ was calculated for each significant effect to determine the proportion of explained variance.

\section{Results}

The serve-return performance was not related to Expertise or Gender. No interaction effect was observed. Participants averaged a serve-return performance of $7.6( \pm 1.7)$ (junior females: $8.7( \pm 1.3)$; junior males: $6.7( \pm 2.8)$; senior females: 7.7 $( \pm 1.1)$; senior males: $7.3( \pm 1.4)$. Regarding the percentage of returns in the court, data were transformed by means of angular transformation (arcsine transformation) prior to performing an ANOVA. No main effects of Expertise and Gender, nor an interaction effect was found. Participants averaged 50.0\% $( \pm 18.3)$ of returns in the court.

The five serve-return events were plotted against the time from stroke and the variability of time from stroke in Figures 2 and 3. Tables 1 and 2 display the ANOVA results. The ANOVAs for split-step take-off, split-step landing and their variability revealed no main effects of Expertise and Gender, nor an interaction effect. 
Participants averaged a take-off time of $9 \mathrm{~ms}( \pm 36)$ and a landing time of $152 \mathrm{~ms}( \pm 25)$ after server-racket ball contact.

The ANOVA for split-step duration revealed no main effects of Expertise and Gender, nor an interaction effect. The standard deviation of this variable, however, revealed a main effect of Expertise $\left(\mathrm{F}_{1,18}=5.85, \mathrm{p}=.026\right.$, alphadj $\left.=.006, \eta_{\mathrm{p}}{ }^{2}=0.25\right)$, with significantly lower variability in seniors $(18 \mathrm{~ms} \pm 4)$ than in juniors $(25 \mathrm{~ms} \pm 8)$, but the significance fell outside of the conservative Holm-Bonferroni limits. The ANOVAs for initial racket movement and its variability revealed no main effects of Expertise and Gender, nor an interaction effect. Participants averaged an initial racket movement of $187 \mathrm{~ms}( \pm 22)$.

A main effect of Expertise $\left(F_{1,18}=6.49, p=.020\right.$, alphaadj $\left.=.005, \eta_{p}{ }^{2}=0.26\right)$ was found for initial foot movement, showing significantly shorter time in seniors (266 ms \pm 43 ) than in juniors (311 $\mathrm{ms} \pm 33$ ), but the significance fell outside of the conservative Holm-Bonferroni limits. No other main effect or interaction effect was observed. The ANOVA for initial foot movement variability only revealed a significant main effect of Gender $\left(F_{1,18}=5.15, \mathrm{p}=.036\right.$, alphaadj $\left.=.006, \eta_{\mathrm{p}}^{2}=0.22\right)$, showing significantly lower foot orientation variability in males $(47 \mathrm{~ms} \pm 19)$ than females (64 $\mathrm{ms} \pm 13$ ), but the significance fell outside of the conservative Holm-Bonferroni limits.

\section{Discussion}

The results revealed no significant difference between the four groups for the proportion of returns in the court and for serve-return performance. This indicates that the experimental task was similar for all participants as they faced a server from their own training group, enabling comparisons of return behaviours that emerged under spatiotemporal conditions commensurate with each participant level. The proportion 
of returns in the court of $50 \%$ was lower than the $80 \%$ reported by Gillet et al. (2009), but the latter corresponded to matches played on a slower court-surface (clay) and included first and second serves. The rather low serve-return performance scores in the present experiment is presumably due to the fact that the serves were fast and directed to the corners of the service box, since serving hard to these two locations is associated with higher percentage of wining points for the server in professional tennis (Mecheri, Rioult, Mantel, Kauffmann, \& Benguigui, 2016). Having severe spatiotemporal constraints was our decision in order to study return behaviours in the most demanding situations while ensuring the task conditions were representative of the performance contexts to which our data are intended to be generalised (Dicks, Davids, \& Button, 2009).

Analysis revealed that the timings of split-step take-off and landing were similar across the four groups of participants. The absence of an expertise effect was in accordance with Avilès et al. (2002). The results thus reveal the well-integrated nature of the scaling of the timing of the split-step in players with considerable levels of practice. The mean values indicated a take-off around the ball stroke (+9 ms) and a landing clearly after it (+152 ms). These values are similar to those recorded by Avilès et al. (2014) in junior players with a take-off initiated $+34 \mathrm{~ms}$ after impact and a landing at $+151 \mathrm{~ms}$.

The split-step duration of $142 \mathrm{~ms}$ in the present study confirms the shortest split-step duration (117 ms) observed by Avilès et al. (2014), but this finding is in contrast with the $200 \mathrm{~ms}$ duration found in Avilès et al. (2002; take-off and landing at -40 and $+160 \mathrm{~ms}$, respectively). It is to be noted that the study of Aviles et al. (2002) was conducted with players of lower level of performance. If future research were to confirm shorter split-step durations for world-class players compared with national or 
regional players, then this would add further evidence to suggestions that such behaviour reflects an adaptation of world-class players to cope with higher spatiotemporal constraints caused by the increase in service speeds in elite tennis (Cross \& Pollard, 2009). A short jump duration might also reflect an improved synchronisation of the split-step with the server's action.

It is also noteworthy that senior players had a marginally-significant lower variability than juniors. An additional amount of practice may have resulted in more stable responses. This could be interpreted as a better attunement to the opponent's action in order to avoid landing too early, when information specifying the direction of the serve is not available, or too late, which would result in insufficient time to reach the ball (Navia et al., 2017). In this regard, it is also interesting to note from Figure 2 that split-step landing was the measure with the smallest variability in the present experiment.

With respect to landing time, it is worth emphasising that our results contrast with the findings from laboratory studies, which reported later landing times when participants were required to produce a quick and reliable lateral step (180 $\mathrm{ms}$ in Uzu et al., 2009; 208 ms in Nieminen et al., 2014). It was previously demonstrated by using a ball projection machine in cricket and tennis that the absence of advanced information sources from an opponent's actions leads to significant delays in movement initiation when compared with a live opponent (see Pinder, Renshaw, \& Davids, 2009; Shim et al., 2005). In laboratory studies, if the use of a preparatory signal of successive blinks provides a certain predictability of the onset of the directional information, such discrete stimuli are not meaningful when compared with the information provided by an opponent's action. The presence of advance information and the ability of players to use it (Farrow \& Abernethy, 2003) likely led 
to an earlier landing with a subsequent reliable lateral response (less than $5 \%$ of "wrong-foot" responses were observed) in our study.

The results showed no significant difference in the time of initial racket movement across the four groups, with a mean value of $187 \mathrm{~ms}$. Given that initial racket movement occurred earlier than initial foot movement in the serve-return time course, this moment corresponds to the first observable orientation of behaviour underpinning the serve-return stroke. The duration between the moment of serving and first racket orientation may be regarded as a decision time, which is perhaps of a short duration considering that a decision is required between at least two directional orientations (Carlton, 1992). If the initial foot movement occurred later than initial racket movement, it appeared that the senior players initiated foot movement towards the intended direction $45 \mathrm{~ms}$ earlier than juniors, enabling them to decrease the time at which they would reach the stroke zone. While the results evidenced a large effect size (Cohen, 1998), this finding should be interpreted with caution since the expertise effect on initial foot movement was only marginally significant.

In sum, on the basis of initial racket movement results, which did not differ between groups, the senior players did not exploit information about future ball direction earlier than juniors. However, the marginally reduced variability in the splitstep duration of senior players suggests a better attunement of the timing of movement relative to the actions of the opponent. The time of initial foot movement was also marginally shorter in seniors allowing a better spatiotemporal coverage of the tennis court. This shorter delay in the initiation of the lateral step may be explained by better neuromechanical capabilities in players with higher expertise. Experiment 2 was designed to examine this issue. 


\section{Experiment 2: Leg Stiffness and Expertise}

The analysis of split-step timing in Experiment 1 revealed that landing and initial response movements occurred after the opponent's ball-racket contact during the serve stroke, highlighting the importance of exploiting information from an opponent's action and ball-flight to return serves in world-class tennis players. As such, waiting as long as possible to exploit more reliable information can support adaptive interceptive behaviour in returning serves. It is therefore plausible that a highly dynamic, fast stretch-shortening cycle movement in world-class players could support their superior serve-return performance in allowing them to wait longer than less-skilled players by using their ability to move quickly after the split-step landing. To assess this possible link, the goal of Experiment 2 was to measure different dynamic lower extremity neuromuscular performance variables during squat, countermovement jumping and a hopping task across different levels of expertise in tennis. Although only limited evidence exists on the relation between Leg Stiffness and expertise in tennis players (see Girard \& Millet, 2009, in young players), it was hypothesised that Leg Stiffness would best discriminate skill-level among the neuromuscular variables (power, jumping performance and leg stiffness), based on findings from other sports (Blickhan, 1989; McMahon \& Cheng, 1990). Although Leg Stiffness is a relatively simple expression of neuromuscular performance as it does not measure directly the return of energy in a stretch shortening cycle, evidence has shown that this measure discriminates expert and novices in jumping and running (for a review, see Brughelli \& Cronin, 2008). It was thus expected that the higher the level of tennis played, the higher the Leg Stiffness in order to increase mechanical efficiency of the split-step.

\section{Method}




\section{Participants}

Thirty-seven male senior tennis players ( 5 of whom took part in Experiment 1 ) were recruited on a voluntary basis to participate in this experiment. Participants were classified into four groups according to their level of expertise (Table 3). The level of expertise was defined according to the French ranking classification, categorised as either world-class players (corresponding to the 50 first French players based on ATP rankings, $\mathrm{n}=6$; 5 took part in Experiment 1 as ATP senior players; these five players were not randomly selected, since their participation depended on their coaches' decision), highly-skilled players (corresponding to a rank between 1,000 to 3,000 in the French national ranking, $n=10$ ), skilled players (corresponding to a rank between 3,000 to $20,000, \mathrm{n}=10$ ) and less-skilled players (corresponding to a rank between 20,000 to $57,000, n=11$ ). A minimum experience of three years in competitive tennis and a minimum training frequency of three times per week were required for recruitment in the skilled and less-skilled players. The experiment was approved by the local ethics committee Human Subject Review Board.

\section{Measurements, Task and Procedure}

For anthropometric measurements, we followed the standardised techniques recommended by the International Society for the Advancement of Kinanthropometry (Marfell-Jones, Olds, Stewart, \& Carter, 2006). Body height was measured using an anthropometer, with $0.1 \mathrm{~cm}$ accuracy. Body mass was measured using bio-electric impedance scales (Weinberger model DJ-156; Weinberger GmbH \& Co, Germany), with $0.1 \%$ accuracy.

Three jumping tasks were performed: 
Hopping on the spot $(\mathbf{5 H})$. Participants were required to hop on the spot five times successively, as high as possible, while reducing the ground Contact Time, with hands on hips.

Squat jump (SJ). After reaching and holding a semi-squat position $\left(90^{\circ}\right.$ knee flexion), this measure required participants to jump as high as possible, with hands on hips.

Countermovement jump (CMJ). Participants were required to jump as high as possible, with hands on hips, after squatting to a freely chosen knee angle.

Participants were equipped with a 3D accelerometric system ("Myotest ${ }^{\circledR}$ ", Myotest S.A., Switzerland; size: $9.5 \times 5.0 \times 1.0 \mathrm{~cm}$; mass: $60 \mathrm{~g}$; sampling frequency: $500 \mathrm{~Hz}$ ). The system was attached to an elastic belt and vertically fixed at hip level in the middle of the lower back during the hopping on the spot, squat jump and countermovement jump tasks. The accuracy of the Myotest device has previously been compared with force plate measures during the assessment of vertical jump height (e.g., Casartelli, Müller, \& Maffiuletti, 2010; Choukou, Laffaye, \& Taiar, 2013). Results indicated that the Myotest underestimated the ground contact time (i.e., the time elapsed between the lowest point of velocity following ground contact and its maximal value during the successive take-off, i.e., when force is equal to body weight $(\mathrm{F}=\mathrm{m} \times \mathrm{g}))$, resulting in a systematic overestimation of the Leg Stiffness (approximately $+2 \mathrm{~cm}$ and $+7.8 \mathrm{kN} . \mathrm{m}^{-}$ ${ }^{1)}$.

The hopping on the spot task was performed to assess Leg Stiffness. The participants were asked to hop on the spot five times (with both limbs) as high as possible while reducing ground Contact Time (Dalleau, Belli, Viale, Lacour, \& Bourdin, 2004). Multiple trials were performed under researcher supervision in order to familiarise participants with the task and to optimise Leg Stiffness. Data were 
recorded only if the bouncing technique was acquired. Leg Stiffness $\left(\mathrm{k}_{\text {leg }}\right)$ corresponded to the ratio of maximal force $\left(\mathrm{F}_{\mathrm{c}}\right.$, when vertical force is equal to zero) relative to the centre of mass displacement $\left(\Delta_{\mathrm{CoM}}\right)$ during grounding (Dalleau et al., 2004). Leg Stiffness was calculated as an absolute (in $\mathrm{kN}^{-1} \mathrm{~m}^{-1}$ ) and relative value, by normalising its absolute value to body mass (in $\mathrm{kN} \cdot \mathrm{m}^{-1} \cdot \mathrm{kg}^{-1}$ ).

$k_{\text {leg }}=F_{c} / \Delta_{C o M}\left(\mathrm{kN} \cdot \mathrm{m}^{-1}\right)$

The Leg Stiffness value was directly calculated by the device. We checked the linearity of the lower limb movements during the ground contact time and their correspondence with theoretical linear spring behaviour, in order to ensure that the linearity of the curve of the vertical force as a function of the vertical displacement of centre of mass was verified. An $\mathrm{r}^{2}>.80$ was chosen as a threshold to consider bouncing behaviour as a linear spring oscillation based on studies reporting of lower-limb spring-like behaviour (e.g., $\mathrm{r}^{2}=.81$ and .84 in females and males, respectively; see Laffaye, Choukou, Benguigui, \& Padulo, 2016). All retained jumps met this criterion. Such criterion enabled us to have an accurate value of Leg Stiffness, although this did not permit the measurement of the efficiency of the stretch shortening cycle. In order to perform a countermovement jump, the participants were instructed to flex their knees freely and to jump once as high as possible. For the squat jump test, the participants were asked to bend and hold a semi-squat position $\left(\sim 90^{\circ}\right.$ knee flexion controlled by a $40 \times 40$ set square, maintained by the experimenter, as biofeedback), until an acoustic signal was given, and then to jump, once, as high as possible. Jump height was calculated by the accelerometric system as follows:

$$
H=9.81 \times 100 \cdot\left(t_{v_{\text {minaffepeak }}}-t_{v_{\text {max }}}\right)^{2} / 8
$$

\section{Statistical Analysis}


Five one-way ANOVAs followed by Fisher's post-hoc test (or Kruskal-Wallis test followed by Dwass-Steel-Critchlow-Fligner pairwise comparisons in variables with homogeneity violations) were applied for the comparison of the four groups. The alpha level was set at .05. As in Experiment 1, the Holm-Bonferroni correction was applied. The assumption of homogeneity of variances was checked using a Levene test. Partial eta-squared $\left(\eta_{\mathrm{p}}^{2}\right)$ or eta-squared (for Kruskal-Wallis test, $\eta^{2}$ ) was calculated for each significant effect to determine the proportion of explained variance.

\section{Results}

Leg Stiffness revealed significant differences between groups, in both absolute $\left(\right.$ ANOVA: $\mathrm{F}_{3,33}=8.04, \mathrm{p}<.001$, alphaadj $\left.=.010, \eta_{\mathrm{p}}{ }^{2}=0.42\right)$ and relative values (Kruskal-Wallis: $\mathrm{H}_{3}=11.15, \mathrm{p}=.011$, alphaadj $=.013, \eta^{2}=0.31$ ). The other tests did not reveal any significant differences (see Table 4). Mean absolute Leg Stiffness ranged from $39.5 \mathrm{kN} . \mathrm{m}^{-1}( \pm 12.9)$ for the less-skilled players to $63.3 \mathrm{kN} \cdot \mathrm{m}^{-1}( \pm 15.4)$ for the world-class players, and from $567.2 \mathrm{kN} \cdot \mathrm{m}^{-1} \cdot \mathrm{kg}^{-1}( \pm 183.7)$ to $789.1 \mathrm{kN} \cdot \mathrm{m}^{-1} \cdot \mathrm{kg}^{-1}$ $( \pm 223.9)$ when normalised. Pairwise comparisons revealed that world-class and highly-skilled players both had significantly higher Leg Stiffness than skilled and lessskilled players. Regarding relative Leg Stiffness, world-class and highly-skilled players both had significantly higher scores than skilled players.

\section{Discussion}

The aim of Experiment 2 was to assess the contribution of several neuromuscular variables towards expertise levels in tennis. The recorded Leg Stiffness values for skilled $\left(37.0 \mathrm{kN} \cdot \mathrm{m}^{-1}\right)$ and less-skilled $\left(39.5 \mathrm{kN} . \mathrm{m}^{-1}\right)$ groups were similar to those reported by Durand et al. (2010) with participants of a similar level of expertise. 
World-class $\left(63.3 \mathrm{kN} \cdot \mathrm{m}^{-1}\right)$ and highly-skilled $\left(55.0 \mathrm{kN} . \mathrm{m}^{-1}\right)$ players had higher values of Leg Stiffness than those calculated in younger players during hopping $\left(18.8 \mathrm{kN} . \mathrm{m}^{-}\right.$ 1, Maquirriain, 2013) and hopping and jumping (19.9 kN.m ${ }^{-1}$, Girard \& Millet, 2009), as well as lower level adults during hopping and jumping $\left(34.8 \mathrm{kN} \cdot \mathrm{m}^{-1}\right.$, see Durand et al., 2010). As hypothesised, Leg Stiffness differentiated world-class and highly-skilled players that compete at national and international level from skilled and less-skilled players that compete at a comparatively lower level.

The absence of significant differences between world-class and highly-skilled players in the current study could be due to high intra-group variability in these two groups. From these results and a previous study, we hypothesise that a Leg Stiffness threshold of $50 \mathrm{kN} \cdot \mathrm{m}^{-1}$ in hop-like actions may be a threshold for fast, elite level racquet sports. This value is close to findings for elite badminton players (Phomsoupha \& Laffaye, 2017), with Leg Stiffness values reported of $52.5 \pm 5.4 \mathrm{kN} . \mathrm{m}^{-1}$ using the same methodology as the current study. The spatiotemporal demands are comparable between both badminton and tennis, with elite badminton shuttle speeds reaching 70 m.s ${ }^{-1}$ following a smash (Phomsoupha \& Laffaye, 2014) compared with $55 \mathrm{~m} . \mathrm{s}^{-1}$ for elite tennis serves (Cross \& Pollard, 2009).

The increase in Leg Stiffness in the two highest levels of tennis players in this study may be due to the many maximal actions that occur during tennis such as fast sprints and jumps for serves and smashes and the numerous split-steps that precede all strokes. These actions require a reactive stretch-shortening cycle and consequently high visco-elastic properties of lower-limb muscles. Durand et al. (2010) reported that Leg Stiffness explained 58\% of the variance with performance in countermovement jump in tennis players with a similar level of expertise to our skilled and less-skilled groups. The split-step allows players' to behave like a linear spring by bouncing stiffly 
in the direction of the ball. Indeed, in a laboratory-based study, Uzu et al. (2009) and Nieminen et al. (2014) showed that players executed faster movements in a split-step condition when compared with a no split-step condition. The split-step allows a reduced response time and muscular pre-activation, both of which are factors that support performance as they facilitate faster movements to intercept the ball. On this basis, one can expect that players who have the best neuro-muscular capacities can afford to wait longer before initiating their action, which in turn enables them to rely on more reliable information (Dicks et al., 2010). This was the goal of the additional analysis between the two sets of experimental data presented below.

\section{Cross-Experiment Analysis: Linking Split-Step Timing and Neuromechanical}

\section{Factors}

Experiment 1 revealed that players with a higher level of expertise tended to initiate the lateral step after landing with less time from service impact than juniors, while Experiment 2 revealed an increase in Leg Stiffness with level of expertise. In this section, the relationship between the timing of the return sequence and neuromechanical indicators were investigated for a better understanding of the movement control mechanisms used by world-class players. In line with previous findings showing that faster goalkeepers tended to wait later before initiating movement in comparison with slower goalkeepers (Dicks et al., 2010), it was hypothesised that world-class tennis players will scale the timing of their split-step to their own neuromechanical capabilities (van Andel, Cole \& Pepping, 2017).

To test this hypothesis, we focused on a sample of ten word-class male players (i.e., the five ATP seniors that took part in both experiments, and the five ITF juniors that took part in Experiment 1, but were also tested following the same protocol 
adopted in Experiment 2). Correlation analyses were performed between performance in countermovement jump and squat jump as predictor variables (Contact Time, Leg Stiffness, Relative Leg Stiffness, CMJ Height and SJ Height) and split-step timing as the dependant variables (Split-step take-off, Split-step landing, Split-step duration, initial racket movement and initial foot movement).

The results revealed a significant correlation between the value of the normalised Leg Stiffness and the time of initial foot movement $\left(\mathrm{r}^{2}=.54, \mathrm{p}<.05\right.$, Figure 4). Although it should be noted that this significant relation is modest in size since small samples can produce inflated correlations (Yarkoni, 2009), and that the use of juniors and seniors violates random sampling assumptions, the result highlights that the players who had the higher Leg Stiffness appeared to initiate their displacement later than the players who had lower Leg Stiffness.

\section{General Discussion}

The present study investigated the split-step timing of world-class tennis players (Experiment 1), the neuromechanical parameters of world-class and lessskilled tennis players (Experiment 2), and whether the split-step timing was related to the players' neuromechanical capabilities (cross-experiment analysis). In Experiment 1, results revealed that the split-step sequence appears to be a well-learned preparatory behaviour, due to consistent take-off (around the ball stroke) and landing (around 150 ms) times across the four groups. As predicted, the mean landing time and the first orientation of the response (racket) occurred after initial ball flight. This coincided with the pick-up of reliable kinematic and ball-flight information about ball direction, leading to a small number of wrong-foot responses (less than 5\%). Notably, the landing time necessary for quick and reliable actions was shorter than previous laboratory 
estimates (180-208 ms) that were obtained in the absence of advance kinematic information (Nieminen et al., 2014; Uzu et al., 2009). This point emphasises that interceptive actions must be assessed in a representative task design, wherein athletes are allowed to function naturally to provide a full picture of skilled performance in perceptual-motor tasks (Dicks et al., 2009; Pinder, Davids, Renshaw, \& Araújo, 2011). In the serve-return time course, while the moment of racket movement initiation was similar between the four groups, a marginally-significant effect of expertise revealed that senior players initiated the lateral step with shorter time than juniors, which raised the question whether such behaviour is due to better neuromechanical capabilities.

Experiment 2 showed that the neuromechanical capabilities of male tennis players were related to their level of expertise. World-class and highly-skilled players both had significantly higher Leg Stiffness than skilled and less-skilled players, with the values of world-class and highly-skilled players comparable to those observed in other racket sports such as badminton, which necessitate high levels of efficiency during the stretch shortening cycle (Phomsoupha \& Laffaye, 2017). Such lower-limb properties are likely a consequence of extensive tennis practice, which are developed through high-intensity running, jumping, and specific strength training (Laffaye et al., 2016). This suggests that Leg Stiffness may be one of the key variables in tennis performance, as it likely contributes to shorter times for the initiation of displacements to intercept the ball. Future research should strive to confirm this finding with prospective data or measure other variables like strength that might explain the association between apparent Leg Stiffness and performance level in tennis.

The cross-experiment analysis revealed a significant relationship between $L e g$ Stiffness and initial foot movement in world-class players, showing later initiation of lateral displacement in the players who had higher Leg Stiffness. Although the small 
sample size limits the strength of evidence for this finding, it is in line with previous behavioural results in time-constrained interceptive tasks showing that skilled performers scale the timings of their response relative to their action capabilities (Dicks et al., 2010; see also van Andel et al., 2017). The results therefore support the view that world-class tennis players with higher lower-limb neuromuscular capabilities - and therefore, better ability to cover the court - initiated their displacement later to exploit more reliable sources of information arising from the final moments of the opponent's serve and early ball-flight. Nonetheless, it would be necessary to follow up this analysis on a larger scale with a higher number of worldclass tennis players as an extension of this study, but also through a prospective study examining the suitability of the neuromuscular factors considered in the present study.

On a practical level, our findings shed new light on the potential importance of training Leg Stiffness in order to enhance serve-return performance (see Wilson, Dicks, Milligan, \& Alder, 2019, for a recent study in soccer). Spending more time in training Leg Stiffness in young players' programs would not only increase their court coverage, but may also provide them with the flexibility to use different information-movement couplings to rely on more reliable information when controlling their interceptive actions. This is hypothesised to provide more adaptability in players across their development (Savelsbergh \& Wormhoudt, 2019).

The findings of this study can also serve as a reference point for practitioners who seek to develop improvements in tennis serve returns. In the current study worldclass players were found to initiate the split-step slightly after the ball stroke and used a shorter subsequent split-step duration to synchronise with the opponent's unfolding action. Subsequently, training aimed at improving both Leg Stiffness properties (see Wilson et al., 2019) as well as the scaling of the split-step timing relative to an 
opponent's serve may be meaningful, since such improvements would possibly help junior players to refine their synchronisation to the opponent's serve and to cope with increasing serve velocities during their development. Training the timing of the splitstep sequence as well as its neuro-muscular efficiency should be also a new objective as it provides a potential to gain the milliseconds which make a difference in the production of efficient responses and shots in the high level competition. Future research geared towards these lines of enquiry would help to better understand the factors that underpin expert interceptive actions in elite sport.

\section{Acknowledgments}

This research was supported by funding from the Institut National du Sport, de l'Expertise et de la Performance (INSEP, grant number 12R36). The authors are grateful to the French Tennis Federation (FFT) for the partnership and the support for the research project and the experiments. They also thank staff from the FFT Bernard Pestre, Paul Quetin, Pascal Supiot and Laurent Raymond. The authors are also grateful to Heloïse Baillet, Franck Bouzard, Maroua Mallek, Cynthia Mandil, Dominic Orth and Régis Thouvarecq for their help during the experiments.

\section{Declaration of Interest Statement}

The authors report no conflict of interest. 
Abernethy, B. (1991). Visual search strategies and decision-making in sport. International Journal of Sport Psychology, 22(3-4), 189-210.

Abernethy, B., \& Wollstein, J. (1989). Improving anticipation in racquet sports. Sports Coach, 12(4), 15-18.

Avilés, C., Benguigui, N., Beaudoin, E., \& Godart, F. (2002). Developing early perception and getting ready for action on the return of serve. ITF Coaching \& Sport Science Review, 28, 6-8.

Avilés, C., Pérez, L. R., Sanz, D., \& Navia, J. (2014). Adaptive and reactive skills involved in the return of serve in tennis. ITF Coaching \& Sport Science Review, 64, 6-8.

Blickhan, R. (1989). The spring-mass model for running and hopping. Journal of Biomechanics. 22, 1217-1227.

Brughelli, M., \& Cronin, J. (2008). A review of research on the mechanical stiffness in running and jumping: methodology and implications. Scandinavian Journal of Medicine \& Science in Sports, 18(4), 417-426.

Carlton, L. G. (1992). Visual processing time and the control of movement. In L Proteau \& D Elliott (Eds.), Vision and Motor Control (pp. 3-31). Amsterdam: Elsevier Science.

Casartelli, N., Müller, R., \& Maffiuletti, N.A. (2010). Validity and reliability of the myotest accelerometric system for the assessment of vertical jump height. Journal of Strength and Conditioning Research, 24, 3186-3193

Choukou, M. A., Laffaye, G., \& Taiar, R. (2013). Validity of an accelerometric system for measuring force-time-based data during jumping tasks. Computer Methods in Biomechanics and Biomedical Engineering, 16, 84-85.

Cohen, J. (1998). Statistical power analysis for the behavioral sciences (2nd ed.). Hillsdale, NJ: Erlbaum.

Cross, R., \& Pollard, G. (2009). Grand Slam men's singles tennis 1991-2009 Serve speeds and other related data. ITF Coaching \& Sport Science Review, 49, 8-10.

Dalleau, G., Belli, A., Viale, F., Lacour, J-R.R., \& Bourdin, M. A. (2004). A simple method for field measurements of leg stiffness in hopping. International Journal of Sports Medicine, 25, 170-176.

Dicks, M., Davids, K., \& Button, C. (2010). Individual differences in the visual control of intercepting a penalty kick in association football. Human Movement Science, 29(3), 401-11.

Dicks, M., Davids, K., \& Button, C. (2009). Representative task design for the study of perception and action in sport. International Journal of Sport Psychology, 40(4), 506. 
Durand, S., Ripamonti, M., Beaune, B. \& Rahmani, A. (2010). Leg ability factors in tennis players. International Journal of Sports Medicine, 31, 882-886.

Fajen, B. R. (2005). Perceiving Possibilities for Action: On the Necessity of Calibration and Perceptual Learning for the Visual Guidance of Action. Perception, 34(6), 717-740.

Farrow, D., \& Abernethy, B. (2003). Do expertise and the degree of perception-action coupling affect natural anticipatory performance? Perception, 32(9), 1127-1140.

Farrow, D., \& Reid, M. (2012). The contribution of situational probability information to anticipatory skill. Journal of Science and Medicine in Sport, 15(4), 368-373.

Girard, O., \& Millet, G.P. (2009). Physical determinants of tennis performance in competitive teenage players. Journal of Strength and Conditioning Research; 23: 1867-1872

Girard, O., Lattier, G., Micallef, J.-P., \& Millet, G.P. (2006). Changes in exercise characteristics, maximal voluntary contraction, and explosive strength during prolonged tennis playing. British Journal of Sports Medicine, 40, 521-526.

Laffaye, G., Choukou, M. A., Benguigui, N., \& Padulo, J. (2016). Age-and gender-related development of stretch shortening cycle during a sub-maximal hopping task. Biology of Sport, 33(1), 29.

Laffaye, G., Taiar, R., \& Bardy, B. G. (2005). The effect of instruction on leg stiffness regulation in drop jump. Science and Sport, 20, 136-143.

Maquirriain, J. (2013). The interaction between the tennis court and the player: how does surface affect leg stiffness? Sports Biomechanics, 12(1), 48-53.

Marfell-Jones, M. J., Olds, T., Stewart, A. D., \& Carter, L. (2006). International standards for anthropometric assessment. Potchefstroom, South Africa: International Society for the Advancement of Kinanthropometry (ISAK).

McMahon, T. A., \& Cheng, G. C. (1990). The mechanism of running: how does stiffness couple with speed? Journal of Biomechanics. 23, 65-78.

Mecheri, S., Rioult, F., Mantel, B., Kauffmann, F., \& Benguigui, N. (2016). The serve impact in tennis: First large-scale study of big Hawk-Eye data. Statistical Analysis and Data Mining: The ASA Data Science Journal, 9(5), 310-325.

Navia, J. A., Dicks, M., van der Kamp, J., \& Ruiz, L. M. (2017). Gaze control during interceptive actions with different spatiotemporal demands. Journal of Experimental Psychology: Human Perception and Performance, 43(4), 783-793.

Nieminen, M. J. J., Piirainen, J. M., Salmi, J. A., \& Linnamo, V. (2014). Effects of neuromuscular function and split step on reaction speed in simulated tennis response. European Journal of Sport Science, 14(4), 318-326. 
Pinder, R. A., Davids, K., Renshaw, I., \& Araújo, D. (2011). Representative learning design and functionality of research and practice in sport. Journal of Sport \& Exercise Psychology, 33(1), 146-55.

Pinder, R. A., Renshaw, I., \& Davids, K. (2009). Information-movement coupling in developing cricketers under changing ecological practice constraints. Human Movement Science, 28(4), 468-479.

Phomsoupha, M., \& Laffaye, G. (2014). Shuttlecock velocity during a smash stroke in badminton evolves linearly with skill level. Computer Methods in Biomechanics and Biomedical Engineering, 17(sup1), 140-141.

Phomsoupha, M., \& Laffaye, G. A. (2017). A multiple repeated sprint ability test with four changes of direction for badminton players (part 2): predicting skill level with anthropometry, strength, shuttlecock and displacement velocity. Journal of Strength \& Conditioning Research. Epub ahead of print, https://doi.org/10.1519/jsc.0000000000002397

Rowe, R. M., \& McKenna, F. P. (2001). Skilled anticipation in real-world tasks: Measurement of attentional demands in the domain of tennis. Journal of Experimental Psychology: Applied, 7(1), 60-67.

Savelsbergh, G. J. P., \& Wormhoudt, R. (2019). Creating adaptive athletes: The Athletic skills model for optimizing physical literacy. Movement and Sport Sciences - Science \& Motricité. Epub ahead of print, https://doi.org/10.1051/sm/2019004

Shim, J., Carlton, L. G., Chow, J. W., \& Chae, W.-S. (2005). The use of anticipatory visual cues by highly skilled tennis players. Journal of Motor Behavior, 37(2), 164-175.

Triolet, C., Benguigui, N., Le Runigo, C., \& Williams, A. M. (2013). Quantifying the nature of anticipation in professional tennis. Journal of Sports Sciences, 31(8), 820-30.

Uzu, R., Shinya, M., \& Oda, S. (2009). A split-step shortens the time to perform a choice reaction step-and-reach movement in a simulated tennis task. Journal of Sports Sciences, 27(12), 1233-1240.

van Andel, S., Cole, M. H., \& Pepping, G.-J. (2017). A systematic review on perceptualmotor calibration to changes in action capabilities. Human Movement Science, 51, 5971.

Van der Kamp, J., Rivas, F., Doorn, H. van, Savelsbergh, G., \& Bennett, S. (2008). Ventral and dorsal system contributions to visual anticipation in fast ball sports. International Journal of Sport Psychology, 39(2), 100-130.

Williams, A. M., \& Ward, P. (2007). Anticipation and Decision Making: Exploring New Horizons. In G. Tenenbaum \& R. C. Eklund (Eds.), Handbook of Sport Psychology (pp. 203-223). John Wiley \& Sons. 
106 Wilson, R., Dicks, M., Milligan, G. \& Alder, D. B. (2019). An Examination of Action 107 Capabilities and Movement Time during a Soccer. Movement and Sport Sciences 108 Science \& Motricité. Epub ahead of print, https://doi.org/10.1051/sm/2019001

109 Yarkoni, T. (2009). Big correlations in little studies: Inflated fMRI correlations reflect low statistical power - Commentary on Vul et al. (2009). Perspectives on Psychological $111 \quad$ Science, 4, 294-298. 
112 Table 1. Main and interaction effects for the temporal variables.

113

114

\begin{tabular}{|c|c|c|c|c|c|c|c|c|c|c|c|c|c|c|c|}
\hline \multirow[b]{2}{*}{ Variables } & \multicolumn{3}{|c|}{ Take-off } & \multicolumn{3}{|c|}{ Landing } & \multicolumn{3}{|c|}{ Duration } & \multicolumn{3}{|c|}{ Racket Initiation } & \multicolumn{3}{|c|}{ Foot Initiation } \\
\hline & $F$ & $p$ & $\eta_{p}^{2}$ & $F$ & $p$ & $\eta_{p}^{2}$ & $F$ & $p$ & $\eta_{p}^{2}$ & $F$ & $p$ & $\eta_{p}^{2}$ & $F$ & $p$ & $\eta_{p}^{2}$ \\
\hline Expertise & 0.92 & 0.35 & 0.05 & 0.01 & 0.92 & 0.00 & 0.98 & 0.33 & 0.05 & 0.14 & 0.71 & 0.01 & 6.49 & $<.05^{*}$ & 0.26 \\
\hline Gender & 0.00 & 1.00 & 0.00 & 0.60 & 0.45 & 0.03 & 0.32 & 0.58 & 0.02 & 1.15 & 0.30 & 0.06 & 0.85 & 0.37 & 0.05 \\
\hline Expertise $\times$ Gender & 0.83 & 0.38 & 0.04 & 0.11 & 0.75 & 0.01 & 0.58 & 0.46 & 0.03 & 2.42 & 0.14 & 0.12 & 0.94 & 0.34 & 0.05 \\
\hline
\end{tabular}

115

* denotes p-values that were lower than .05 but higher than Holm-Bonferroni adjusted alpha. 
118 Table 2. Main and interaction effects for the standard deviation of the temporal variables.

119

120

\begin{tabular}{|c|c|c|c|c|c|c|c|c|c|c|c|c|c|c|c|}
\hline \multirow[b]{2}{*}{ Variables } & \multicolumn{3}{|c|}{ SD Take-off } & \multicolumn{3}{|c|}{ SD Landing } & \multicolumn{3}{|c|}{ SD Duration } & \multicolumn{3}{|c|}{$\begin{array}{c}\text { SD Racket } \\
\text { Initiation }\end{array}$} & \multicolumn{3}{|c|}{ SD Foot Initiation } \\
\hline & $F$ & $p$ & $\eta_{p}^{2}$ & $F$ & $p$ & $\eta_{p}^{2}$ & $F$ & $p$ & $\eta_{p}^{2}$ & $F$ & $p$ & $\eta_{p}^{2}$ & $F$ & $p$ & $\eta_{p}^{2}$ \\
\hline Expertise & 0.18 & 0.67 & 0.01 & 0.05 & 0.83 & 0.00 & 5.85 & $<.05^{*}$ & 0.25 & 0.04 & 0.84 & 0.00 & 0.03 & 0.88 & 0.00 \\
\hline Gender & 0.09 & 0.77 & 0.00 & 0.01 & 0.90 & 0.00 & 0.86 & 0.36 & 0.05 & 0.33 & 0.57 & 0.02 & 5.15 & $<.05^{*}$ & 0.22 \\
\hline Expertise $\times$ Gender & 3.94 & 0.06 & 0.18 & 0.78 & 0.39 & 0.04 & 2.06 & 0.17 & 0.10 & 0.45 & 0.51 & 0.02 & 1.40 & 0.25 & 0.07 \\
\hline
\end{tabular}

121

* denotes p-values that were lower than .05 but higher than Holm-Bonferroni adjusted alpha. 
Table 3. Morphological characteristics of the four samples (mean \pm SD).

\begin{tabular}{lccc}
\hline Group (n) & Age (years) & Body Height $(\mathbf{m})$ & Body Mass $(\mathbf{k g})$ \\
\hline Less-skilled (11) & $19.5 \pm 1.8$ & $1.80 \pm 0.05$ & $69.6 \pm 8.2$ \\
Skilled (10) & $19.5 \pm 1.6$ & $1.76 \pm 0.03$ & $69.4 \pm 9.5$ \\
Highly-skilled (10) & $20.7 \pm 2.7$ & $1.82 \pm 0.06$ & $73.6 \pm 8.0$ \\
World-class (6) & $26.6 \pm 4.2$ & $1.86 \pm 0.05$ & $77.0 \pm 7.2$ \\
\hline
\end{tabular}


Table 4. Physical tests results of the four groups.

\begin{tabular}{|c|c|c|c|c|c|}
\hline Group (n) & Contact Time (ms) & Leg Stiffness $\left(k N . m^{-1}\right)$ & Relative Leg Stiffness $\left(\mathrm{kN} \cdot \mathrm{m}^{-1} \cdot \mathrm{kg}^{-1}\right)$ & CMJ Height (cm) & SJ Height (cm) \\
\hline Less-skilled (11) & $154 \pm 40$ & $39.5 \pm 12.9$ & $567.2 \pm 183.7$ & $40.1 \pm 6.2$ & $33.7 \pm 4.4$ \\
\hline Skilled (10) & $147 \pm 15$ & $37.0 \pm 7.6$ & $532.7 \pm 87.2$ & $41.1 \pm 4.1$ & $36.4 \pm 3.5$ \\
\hline Highly-skilled (10) & $136 \pm 22$ & $55.0 \pm 14.5^{(3,4)}$ & $745.6 \pm 164.2^{(3)}$ & $38.3 \pm 5.0$ & $33.2 \pm 4.4$ \\
\hline World-class (6) & $124 \pm 13$ & $63.3 \pm 15.4^{(3,4)}$ & $789.1 \pm 223.9^{(3)}$ & $39.3 \pm 2.6$ & $32.4 \pm 2.2$ \\
\hline ANOVA & $\mathrm{H}(3)=7.30$ & $\mathrm{~F}(3,33)=8.04$ & $\mathrm{H}(3)=11.15$ & $\mathrm{H}(3)=2.34$ & $\mathrm{~F}(3,33)=1.77$ \\
\hline p value & .06 & $<.05 *$ & $<.05^{*}$ & .51 & .17 \\
\hline
\end{tabular}

133 For each group all data (Mean \pm SD): CMJ for countermovement jump; SJ for squat jump; * : significant difference between groups;

$134{ }^{1}$ significantly different than world-class, ${ }^{2}$ significantly different than highly-skilled, ${ }^{3}$ significantly different than skilled and ${ }^{4}$ significantly different 135 than less-skilled players at $p<.05$. 
138

139

140

141

142

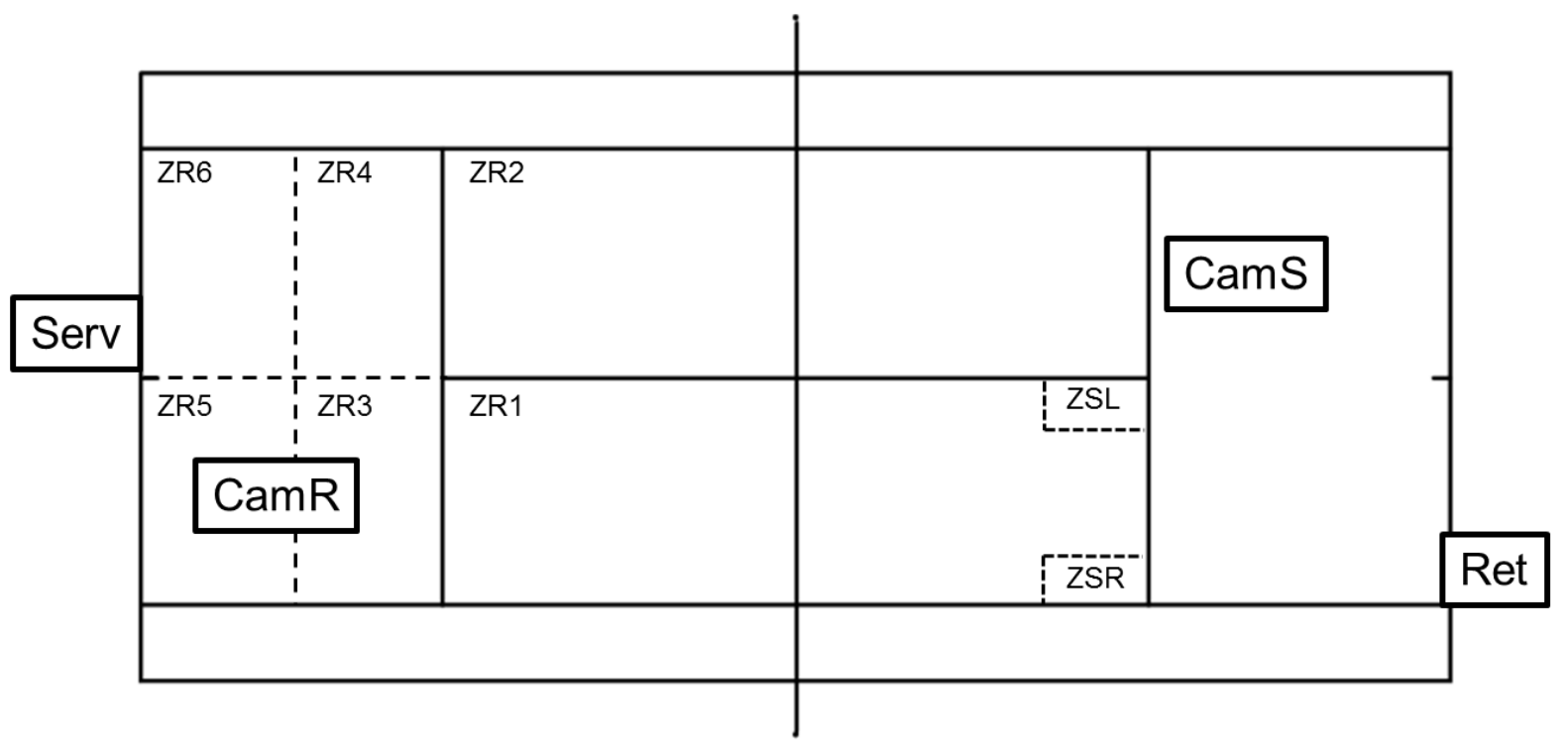

143

144

145

146 
148

149

150

151

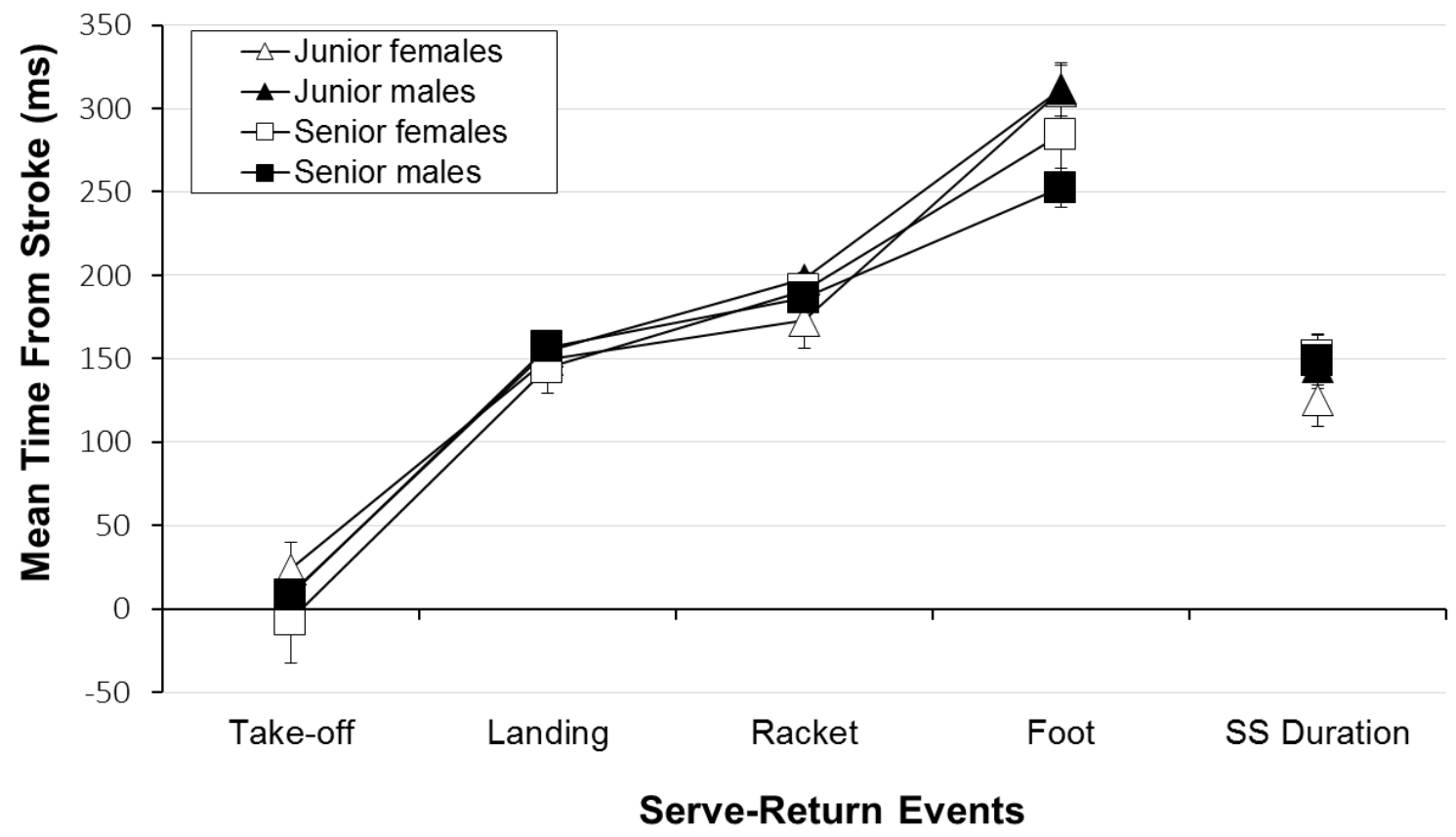

152

153

154

155

156 
158

159

160

161

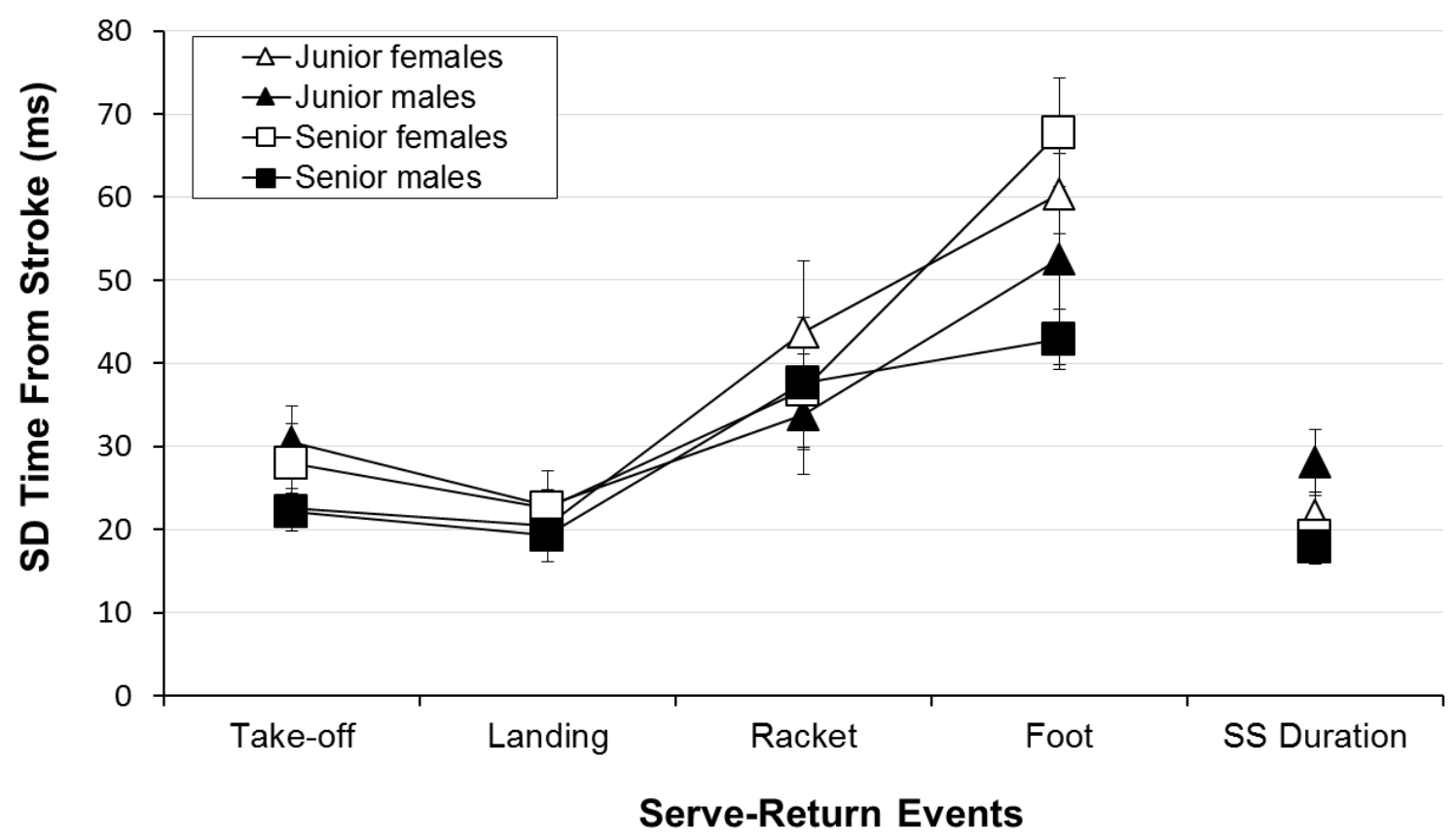

162

163

164

165

166 
168

169

170

171

172

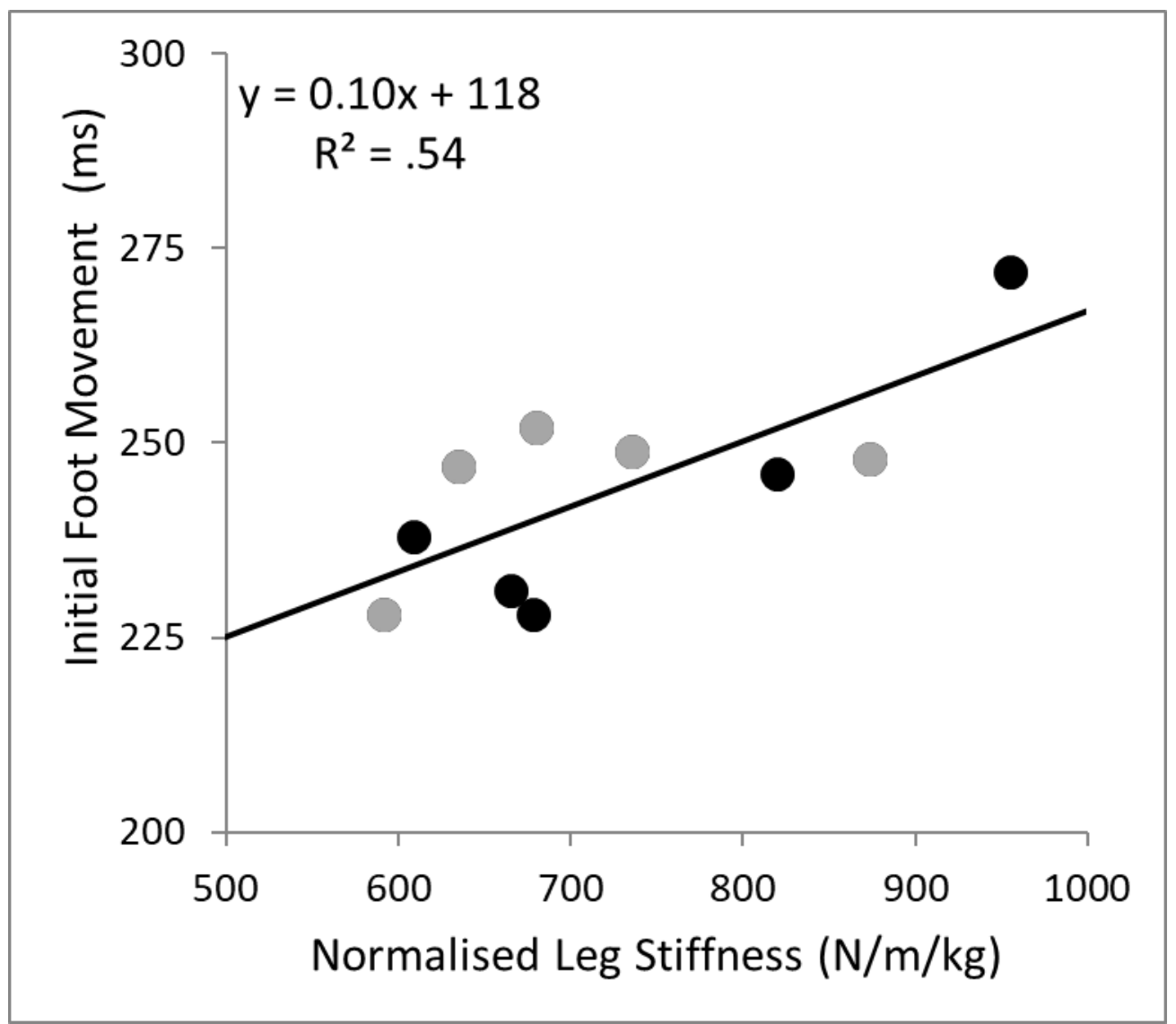

173

174

175 


\section{Figure Captions}

Figure 1. Organisation of the experimental tennis court. Ret: Starting position of the Returner;

180 Serv: Starting position of the Server; CamR: Camera filming the returner; CamS: Camera 181 filming the server; ZSL and ZSR: Left and Right Zones of Serve; ZR1-ZR6: Zones of Return $182(\mathrm{ZR} 6=20$ points, $\mathrm{ZR} 5=16$ points, $\mathrm{ZR} 4=12$ points, $\mathrm{ZR} 3=10$ points, $\mathrm{ZR} 2=8$ points, $\mathrm{ZR} 1=$ 1836 points). Points were also distributed for a stroke out of the court ( 3 points), hitting the net (2 184 points) or that did not reach the net (1 point). Zero points were awarded in the case of an ace 185 (i.e., untouched serve).

Figure 2. Time from stroke of the different serve-return events for male (filled symbols) and female (open symbols) players in juniors (triangles) and seniors (squares). Zero represents the moment of serving (SS is for split-step). The error bars represent the standard error of the mean.

Figure 3. Variability of time from stroke of the different serve-return events for male (filled symbols) and female (open symbols) players in juniors (triangles) and seniors (squares). Zero represents the moment of serving (SS is for split-step). The error bars represent the standard error of the mean.

196 Figure 4. Correlation between Normalised Leg Stiffness and initial foot movement in world197 class players (grey and black points are for juniors and seniors, respectively). 